\title{
Índice de Desempenho Logístico (LPI): uma análise da eficiência logística e da importância relativa dos seus indicadores
}

\section{Logistic Performance Index (LPI): an analysis of logistical efficiency and the relative importance of its indicators}

\author{
Luiz Kennedy Cruz Machado \\ Universidade Federal de Lavras (UFLA) \\ email:luizken@yahoo.com.br
}

\section{Antônio Carlos dos Santos}

Universidade Federal de Lavras (UFLA)

email:acsantos@ufla.br

\section{RESUMO}

A presente pesquisa avaliou a eficiência logística dos países, bem como criar scores que represente o peso de cada indicador do Índice de Desempenho Logístico (LPI) nessa eficiência. A Análise Envoltória de Dados (DEA) foi empregada na mensuração da eficiência logística e permitiu comparar os seis indicadores do LPI (inputs) de 99 países e mostrar a relação desses indicadores com o Produto Interno Bruto per capta (output). Para a criação dos scores utilizou-se da estatística multivariada com a análise discriminante para elucidar quais indicadores melhor discriminam os grupos dos países mais e menos eficientes no quesito logístico. Os resultados agruparam os níveis de eficiência logística dos países em faixa inferior, mediana e superior de eficiência, enquanto a análise discriminante apresentou os indicadores LPI que mais impactam no desempenho logístico, sendo a Alfândega, a Infraestrutura e os Carregamentos Internacionais os indicadores mais significativos na busca pela eficiência logística máxima dos países.

Palavras-Chave: Eficiência logística. Índice de desempenho logístico. Análise Envoltória de Dados. Análise Discriminante.
This research evaluated the logistical efficiency of the countries, as well as creating scores that represent the weight of each indicator of the Logistic Performance Index (LPI) in this efficiency. The Data Envelopment Analysis (DEA) was used to measure logistical efficiency and made it possible to compare the six LPI indicators (inputs) from 99 countries and show the relationship of these indicators with the Gross Domestic Product per capita (output). For the creation of the scores, multivariate statistics were used with the discriminant analysis to elucidate which indicators better discriminate the groups of the countries that are more and less efficient in terms of logistics. The results grouped the levels of logistical efficiency of the countries in the lower, median and upper efficiency ranges, while the discriminant analysis showed the LPI indicators that most impact logistics performance, with Customs, Infrastructure and International Shipments being the most significant indicators in search for maximum logistical efficiency in the countries.

Key-words: Logistic efficiency. Logistic Performance Index. Data Envelopment Analysis. Discriminant analysis. 


\section{INTRODUCTION}

O fenômeno da globalização econômica provocou e provoca mudanças em todo mercado, da produção ao consumo, incorrendo em competitividade acirrada entre as empresas e países. Essa situação trouxe a necessidade de as empresas estabelecerem novas estratégias para garantir uma melhor posição no mercado, dentre elas as ligadas a logística e seu desempenho.

A logística desempenha cada vez mais um papel central nas relações comerciais nacionais e internacionais, ela vem sendo utilizada como instrumento que possibilita o desenvolvimento de diferenciais competitivos pois visa identificar as oportunidades de melhoria dos processos, a redução dos custos das atividades que compõem a cadeia de valor e a maximização dos resultados.

A partir da evolução tecnológica e do comércio internacional dos anos de 1980, pesquisadores têm estudado os fatores que determinam ou influenciam a qualidade da prática logística, sendo, em sua grande maioria, direcionadas para a mensuração do desempenho logístico das organizações (BAZANI, 2017).

A partir do desempenho logístico é possível avaliar a atratividade de países de interesse e verificar as qualidades e dificuldades desses serviços. Essa análise é fundamental para se mensurar as oportunidade e ameaças que possam surgir nas transações internacionais e o impacto que a estrutura logística dos países tem nas transações comerciais. Para Marin et al. (2019), esse desempenho é uma parte da performance das organizações que tem fascinado muitos pesquisadores nos últimos anos, com diferentes pesquisas e definições do termo.

O desempenho logístico pode ser mensurado por meio de indicadores que refletem os resultados da organização ou do país, tanto nas questões internas como nas externas relacionadas a atuação no cenário internacional. Esses indicadores agem como parâmetros de comparação interorganizacional. Um conjunto de indicadores amplo e bem estabelecido é fundamental para as empresas enfrentarem as ameaças e oportunidades presentes no ambiente competitivo (GOMES; RIBEIRO, 2004).

Contudo, mensurar o desempenho logístico dos países e fazer comparações a partir de indicadores para analisar suas oportunidades de crescimento e competitividade, é algo complexo de se fazer. Diversos países estão utilizando os dados do Índice de Desempenho Logístico (LPI), presentes no relatório Connecting to Compete publicado bianualmente pelo Banco Mundial, como instrumentos de formulação de políticas públicas, pois o índice resume a estrutura logística em um único indicador.

A análise desses indicadores demanda de técnicas para medir a eficiência das empresas/países, que vem evoluindo com a solicitação de dados cada vez mais confiáveis para análises e criação de estratégias. Martí, Martín, Puertas (2017) defendem que somente quando os países estiverem realmente preparados para implementar os avanços que a globalização comercial exige, eles poderão se beneficiar das vantagens que um melhor desempenho logístico pode proporcionar.

Diante do exposto, fica evidente a necessidade de um instrumento quantitativo adequado para medir e comparar a eficiência logística em diferentes partes do mundo. Desta forma a presente pesquisa objetiva avaliar a eficiência logística dos países considerando os aspetos institucionais e estruturais, bem como criar scores que represente o peso de cada indicador LPI nessa eficiência.

Este capítulo está estruturado em cinco seções, incluindo-se esta introdução. No próximo tópico há o referencial teórico como alicerce a elucidar sobre a logística organizacional e seus indicadores de desempenho com foco no Índice de Desempenho Logístico - LPI. Adiante está o percurso metodológico utilizado na pesquisa, seguido dos resultados e discussão. Por fim, são apresentadas as conclusões e as referências bibliográficas.

\section{REFERENCIAL TEÓRICO}

\subsection{Logística e indicadores de desempenho}

Logística remete a parte da cadeia de suprimentos que planeja, implementa e controla, de modo eficiente e eficaz, o fluxo direto e reverso e a armazenagem de bens, serviços e informações relativas desde o ponto de origem até o ponto de consumo de 
modo a atender os requisitos dos clientes, segundo o Council of Supply Chain Management Professionals - (CSCMP, 2009).

A falta de investimentos em infraestrutura logística é apontada como um dos principais gargalos do crescimento econômico do Brasil (CABRAL; SILVA JÚNIOR, 2011). No contexto geral de um país, o crescimento econômico está vinculado ao crescimento de todos os setores de modo coeso, em que o crescimento da indústria e do comércio reflete diretamente no Produto Interno Bruto (PIB) do país.

Investimentos em infraestrutura são vastamente considerados como promotores do crescimento econômico de qualquer nação (CARLSSON; OTTO; HALL, 2013). Eng-Larsson et al. (2012) mostram que o crescimento econômico é comumente considerado o principal fator do aumento do transporte de cargas.

Os indicadores de desempenho logístico funcionam como um parâmetro de comparação interorganizacional, por meio do qual torna-se possível à empresa confrontar seus resultados atuais com os anteriores, além de avaliar-se frente as outras organizações, tanto em termos do seu grau de sucesso quanto de fracasso. Um conjunto de indicadores amplo e bem estabelecido é fundamental para as empresas enfrentarem as ameaças e oportunidades presentes no ambiente competitivo (GOMES; RIBEIRO, 2004).

Os indicadores de desempenho logístico abrangem as atividades logísticas de transporte, aquisição de materiais e peças, gestão de estoque, gestão de armazenagem, gestão da manutenção, engenharia de infraestrutura, e distribuição física (CAVANHA FILHO, 2008). Segundo Rey (1999), os indicadores necessitam ser desenvolvidos de modo criterioso segundo os objetivos que se desejam alcançar.

Bizotto et al. (2011) afirmam que o tempo e a qualidade são aspectos desafiadores da produção nos mercados transnacionais. Os processos de logística tornaram-se importantes devido à sua função estratégica, são realizados de forma sistêmica e refletem na busca da eficiência de satisfazer às demandas dos diversos clientes ao redor do mundo.

Para Bazani (2017), o desempenho logístico reflete os resultados da organização, tanto nos quesitos internos como nos externos relacionados a atuação no cenário nacional e internacional. Os indicadores de desempenho logístico merecem atenção dos agentes exportadores e importadores, além das agências governamentais que atuam nesse cenário institucional.

A gestão da cadeia de suprimentos, no contexto de um país, remete à confiabilidade para expansão do comércio internacional. A relação entre o crescimento do país e seu desempenho logístico evidencia que países de grande atuação logística são considerados mais confiáveis, e, portanto, atraem mais investimentos (WACZIARG; WELCH, 2008).

Segundo Ballou (2006), um sistema que proporciona eficiência nas operações logísticas, principalmente no mercado internacional, se concretiza como responsável pela construção do apoio indispensável para a execução de um comércio promissor e significativo. Os indicadores de desempenho entram nesse contexto como forma de mensuração da eficiência logística e seu impacto nas atividades dos países/ empresas.

\section{2 Índice de Desempenho Logístico (LPI)}

Diante da complexidade em realizar comparações entre países para identificar os principais entraves logísticos, o Banco Mundial começou a publicar no ano de 2007 o relatório Connecting to Compete, com sua segunda edição publicada em 2010 e a partir desse ano com publicação bianual (2012, 2014, 2016, 2018).

Esse relatório fornece um ranking de desempenho logístico nacional e internacional (foco desse trabalho), a partir da criação de um Índice de Desempenho Logístico, do inglês Logistic Performance Index (LPI). O LPI objetiva sintetizar o desempenho logístico dos países por meio de seis indicadores que representam diferentes dimensões do processo logístico e formam um índice geral, são eles: alfândega; infraestrutura; carregamentos internacionais (criado em 2010, antes era representado pelos indicadores de facilidade de carregamento e custos logísticos domésticos); qualidade e competência logística; monitoramento e rastreabilidade; e previsibilidade (BANCO MUNDIAL, 2018).

O LPI é construído usando a Análise de Componentes Principais (PCA), uma técnica estatística usada para reduzir a dimensionalidade de um conjunto de dados, com entradas correspondentes a cada um dos seis componentes e, em seguida, calculando 
a média das pontuações para cada país, onde o PCA fornece um único indicador LPI, estabelecendo um ranking logístico para os países analisados. Os indicadores formam o índice geral e cada um deles tem um peso aproximado de 0,41 nessa composição geral (BANCO MUNDIAL, 2018).

Seguramente as dimensões logísticas têm relações entre elas. O Banco Mundial (2018) considera que os indicadores ligados a ações políticas (fatores institucionais) estão relacionados às entradas da cadeia de suprimento, sendo eles os indicadores alfândega, infraestrutura e qualidade e competência logística. Já os resultados, que compõem a mensuração do desempenho da gestão da cadeia de suprimentos (fatores estruturais), são formados pelos indicadores de carregamentos internacionais, monitoramento e rastreabilidade e previsibilidade.

O relatório do LPI apresenta uma visão mundial sobre o desempenho logístico do comércio em mais de 160 países, na visão dos profissionais de logística. As informações da pesquisa do LPI fornecem dados numéricos e evidencia o quão fácil ou difícil é transportar mercadorias nesses países. Os scores variam de 1 a 5 , sendo pior desempenho e melhor desempenho, respectivamente.

Os produtos cobertos na criação do LPI são os manufaturados, descartando da análise o comércio de matérias-primas e produtos de energia como minério, grãos, petróleo e gás, que utilizam canais diretos (comprador-vendedor) da indústria ou corretores de mercadorias (BANCO MUNDIAL, 2018).

As características de cada um dos indicadores são:

Alfândega: mensura a eficiência da gestão aduaneira e das fronteiras de liberação. Esse indicador de desempenho aborda a eficiência das atividades aduaneiras de rotina, procedimentos de desembaraço aduaneiro tais como: inspeção física, apresentação eletrônica, liberação antes e após a chegada, auditoria e transparência dos procedimentos alfandegários e administrativos (BANCO MUNDIAL, 2018).

- Infraestrutura: remete a qualidade da infraestrutura relacionada ao comércio e transporte de mercadorias. Para Soliani (2018), esse indicador interfere diretamente no fluxo dos processos de comércio internacional, e os custos de transporte, o desempenho das exportações e os fluxos de comércio geralmente dependem da qualidade e infraestrutura dos países.

Qualidade e competência logística: Envolve a atividade de operadores de transporte em todos os modais, despachantes aduaneiros e serviços de expedição em geral, tanto de fornecedores públicos como privados (BANCO MUNDIAL, 2018).

Carregamentos internacionais: analisa a facilidade de organizar remessas com preços competitivos. Avalia a capacidade de preparar o embarque e desembarque de modo eficiente, flexível, previsível e a preços competitivos (BANCO MUNDIAL, 2018).

Monitoramento e rastreabilidade: envolve o controle das mercadorias desde seu local de origem até o ponto de entrega, ressaltando as alterações de rotas e datas que podem ocorrer durante o processo (BANCO MUNDIAL, 2016).

Previsibilidade: para o Banco Mundial (2018), esse indicador avalia a frequência com que as remessas chegam aos consignatários dentro do prazo de entrega programado ou esperado. A previsibilidade também se relaciona com o tipo de modal que será utilizado e com questões ambientais de logística verde, transporte multimodal e o consumo de combustível - eco eficiência (LAU, 2011; MARIANO et al., 2017).

Martí, Puertas e García (2014) concluíram que qualquer um dos seis indicadores do LPI contribui para o crescimento significativo dos fluxos de comércio. Eles analisaram, por meio de um modelo gravitacional, o impacto que cada um dos indicadores tem no comércio de países emergentes situados na África, América do Sul e Leste Europeu, e o avanço do setor logístico nesses países.

Kabak, Ülengin e Ekici (2018) analisam as relações entre os seis indicadores que compõem o LPI de 2016 com as exportações de países em diferentes situações no comércio internacional, como Brasil, Portugal, Turquia, Zimbábue e Burundi. O trabalho constatou que o Brasil necessita melhorar todos os indicadores que compõem o índice para obter um alto 
desempenho em exportações, com ponto crítico nos indicadores de alfândega e previsibilidade.

Embora o LPI esteja sendo vastamente utilizado na última década por pesquisadores e atores políticos para formular medidas políticas, há críticas sobre o método do LPI geral em considerar pesos praticamente iguais aos indicadores, o que parece improvável dentro do complexo sistema de logística atual (REZAEI; VAN ROEKEL; TAVASSZY, 2018). Esses autores desenvolveram um trabalho no qual atribuíram pesos aos seis componentes por meio do procedimento Best Worst Method (BWM), um método de análise de decisão multicritério.

As descobertas de Rezaei, Van Roekel e Tavasszy (2018) atribuíram pesos diferentes aos seis indicadores, que embora tenha apresentado uma diferença sutil no ranking de classificação dos países, devido a correlação entre os indicadores, o trabalho pode apontar aos gestores públicos as prioridades de atenção e investimento entre os indicadores, e sinalizar para os empresários que atuam no comércio internacional onde estão os gaps no sistema logístico dos países. A Infraestrutura foi considerada o componente mais importante para o desempenho logístico, enquanto o Monitoramento e rastreabilidade o fator menos importante.

Gessner, Rodriguez e Lezana (2018) analisam o desempenho logístico do Brasil com base nos LPIs publicados de 2007 a 2018, a partir do método de Rezaei, Van Roekel e Tavasszy (2018). Os autores mostram que a alfândega apresentou o pior desempenho em todos os anos, conforme o LPI divulgado pelo Banco Mundial, carecendo de investimentos. O indicador de previsibilidade obteve o resultado mais significativo, sendo esse apontado como muito relevante em termos de competitividade internacional.

\section{PERCURSO METODOLÓGICO}

Para avaliar a eficiência produtiva a partir do desempenho logístico dos países, considerando os aspetos institucionais e estruturais, bem como criar scores que represente o peso de cada indicador nessa eficiência, utilizou-se a Análise Envoltória de Dados (do termo em inglês Data Envelopment Analysis
- DEA) e a estatística multivariada com a análise discriminante.

Os modelos DEA permitiram comparar os indicadores de eficiência de cada nação no período em questão (benchmark). Foi possível mostrar os mais eficientes na relação entre os indicadores do LPI com o Produto Interno Bruto per capta (PIB per capta).

A princípio, as DMU's (Unidades Tomadoras de Decisão, do inglês Decision Making Unit - DMU) eram representadas pelos países (157 em média) que são ranqueados no LPI. Os seis indicadores que formam o LPI geral foram os insumos (inputs) do processo, enquanto o produto (output) foi a eficiência produtiva, representada pelo Produto Interno Bruto (PIB) per capta desses países em dólar americano, com valor nominal ajustado em relação a inflação (ou deflação) para o ano base de 2010 (BANCO MUNDIAL, 2020).

Em relação ao tamanho da amostra, estudos mais criteriosos recomendam no mínimo uma quantidade de DMUS's duas vezes maior que o número de insumos vezes o de produtos, ou seja, para 6 insumos e 1 produtos devemos ter um número mínimo de DMU's igual a 12 (2 x 6 insumos x 1 produtos) (DYSON et al., 2001; SARKIS, 2007). Esse quesito é atendido com tranquilidade pelos modelos propostos.

A título de comparação e expansão da análise, foi desenvolvida uma DEA para cada um dos três últimos anos de publicação do LPI (2014, 2016 e 2018), totalizando três modelos. As análises de eficiência foram feitas separadamente por modelo e pela média geral desses três anos.

Os valores dos PIBs per capta utilizados foram referentes aos anos anteriores da divulgação do LPI, uma vez que seria mais correto utilizar essa variável referente ao período que os dados LPI foram coletados e não divulgados, ou seja, o LPI do ano de 2014 será comparado com o PIB per capta do ano de 2013 e desta forma para os demais modelos.

Para a operacionalização e análise dos dados, o modelo DEA utilizado foi o CCR (desenvolvido por Charnes, Cooper e Rhodes em 1978), com orientação para output. A análise de resultados foi feita pela fronteira padrão, e o software utilizado para o cálculo da eficiência logística foi o SIAD - Sistema Integrado de Apoio a Decisão. 
Em um segundo momento, a partir desse ranking (foi utilizado um ranking com a média da eficiência dos três anos em análise) de eficiência dos países da amostra, foram criados grupos para distinguir os países mais eficientes dos menos eficientes. $\mathrm{O}$ teste ANOVA demonstra se os grupos apresentam diferenças estatísticas significativas para discriminar os países eficientes dos não eficientes, comparar as médias individuais dos grupos (eficientes e não eficientes) e verificar o poder de discriminação de cada indicador.

No que se refere a criação dos scores se desenvolveu uma análise discriminante na tentativa de elucidar quais variáveis (indicadores) mais discriminam os grupos. Hair et al. (2009) argumentam que ela pode ser vista como uma técnica estatística apropriada quando se tem uma variável dependente e categórica (nominal ou não métrica) e as variáveis independentes são métricas.

A importância de cada variável dentro da função discriminante pode ser compreendida pelo método de análise dos coeficientes padronizados da função canônica (CORRAR; PAULO; DIAS FILHO, 2017). E outro método que permite uma interpretação mais aproximada da importância dos valores reais, conforme Corrar, Paulo e Dias Filho (2017), são os coeficientes não padronizados da função discriminante canônica.

A Equação 1 representa uma combinação linear para a análise discriminante, ou seja, a função discriminante assume a seguinte forma:

$$
Z_{j k}=a+W_{1} X_{1 k}+W_{2} X_{2 k}+\ldots+W_{n} X_{n k}
$$

Em que:

$Z_{j k}=$ variável dependente ou score $Z$ discriminante da função discriminante $j$ para o objeto $k$;

$a=$ intercepto da função quando todo $X_{i}=0$;

$W_{i}=$ peso discriminante para a variável independente $i$;

$X_{i k}=$ variável independente $i$ para o objeto $\mathrm{k}$.

Com base na função discriminante, obtém-se um score $\mathrm{Z}$ discriminante que representa o resultado composto da multiplicação de cada variável independente por seu peso correspondente. A discriminação dos grupos ocorre, por meio do estabelecimento dos pesos da variável estatística (variável predita não métrica), para cada variável preditora, no intuito de maximizar a variância entre os grupos e dentro de cada grupo (MATEUS, 2010).

Vale ressaltar que na função discriminante criada por Fisher, também conhecida como função de classificação, não se utiliza a constante $a$ (intercepto), o que simplifica a interpretação dos valores gerados para $\mathrm{W}_{i}$ em razão de estes se aproximarem dos valores reais quando o intercepto não está presente na função. Por este método, os valores de observação para as variáveis (independentes) são inseridos na função de Fisher e um score de classificação para cada grupo é calculado para aquela observação, então, ela é classificada no grupo com maior escore de classificação (HAIR et al., 2009).

Os outliers foram objetos de atenção visto que eles prejudicam as análises. Corrar, Paulo e Dias Filho (2017) e Field (213) sugerem testes para identificar os outliers e transformá-los ou eliminá-los antes do início dos testes. Neste segundo momento os dados foram tabulados e analisados mediante a utilização do software Statistic Package for the Social Science ${ }^{\varpi}$ (SPSS).

\section{RESULTADOS E DISCUSSÃO}

Nesse tópico, são apresentados os resultados encontrados, tanto no que diz respeito aos modelos de eficiência logística quanto a análise discriminante.

\subsection{Eficiência Logística}

A princípio, os países (DMU's) foram organizados de modo que os mesmos pertençam aos três anos da amostra, totalizando 137 países. Todavia, a fim de obter maior acurácia nos modelos DEA, melhor ajuste ao software SIAD e não distorcer a amostra com países de baixa produção e baixo desempenho logístico, foram retirados os 38 países de menor PIB per capta para o ano de 2018, sendo a amostra final composta por 99 países em cada um dos três anos.

Antes de apresentar os resultados de eficiência e da análise discriminante, apresenta-se a estatística 
descritiva das variáveis incorporadas nas análises, conforme segue na Tabela 1. As variáveis Alf, Inf, QCL, CaI, Mor e Pre representam as variáveis de entradas (inputs) dos modelos DEA, enquanto o PIB per capta é tido como a única variável de saída (output) dos modelos.

Verifica-se que a média das variáveis independentes não apresentaram grandes oscilações ao longo do tempo com uma leve redução dos valores do ano de 2014 para 2018. De modo contrário, a variável de saída PIB apresentou um aumento médio de 6,57\% nesse mesmo período.

Dentre as variáveis de entrada, a Previsibilidade (Pre) apresentou maior média e constância no período, com média em torno de 3,5, menores valores de desvio padrão e coeficiente de variação e máxima $(4,80)$ e mínima $(2,44)$ maiores no período em questão. A variável Alfândega (Alf) apresentou menor média

Tabela 1 Estatística descritiva das variáveis de input e output dos modelos testados.

\begin{tabular}{|c|c|c|c|c|c|c|c|c|}
\hline & & \multicolumn{6}{|c|}{ Input } & \multirow{2}{*}{$\begin{array}{c}\text { Output } \\
\text { PIB per capta }\end{array}$} \\
\hline & & Alf & $\ln f$ & $\mathbf{Q C L}$ & Cal & MoR & Pre & \\
\hline \multirow[t]{3}{*}{ Média } & 2018 & 2,89 & 2,99 & 3,04 & 3,03 & 3,12 & 3,49 & 22025,40 \\
\hline & 2016 & 2,93 & 3,04 & 3,07 & 3,09 & 3,15 & 3,51 & 21345,52 \\
\hline & 2014 & 2,97 & 3,06 & 3,11 & 3,08 & 3,14 & 3,50 & 20667,74 \\
\hline \multirow[t]{3}{*}{ Desvio Padrão } & 2018 & 0,59 & 0,68 & 0,64 & 0,51 & 0,63 & 0,53 & 22131,13 \\
\hline & 2016 & 0,65 & 0,72 & 0,64 & 0,55 & 0,68 & 0,57 & 21573,79 \\
\hline & 2014 & 0,59 & 0,64 & 0,56 & 0,43 & 0,55 & 0,56 & 20834,90 \\
\hline \multirow[t]{3}{*}{ Coeficiente de Variação } & 2018 & 0,20 & 0,23 & 0,21 & 0,17 & 0,20 & 0,15 & 1,00 \\
\hline & 2016 & 0,22 & 0,24 & 0,21 & 0,18 & 0,21 & 0,16 & 1,01 \\
\hline & 2014 & 0,20 & 0,21 & 0,18 & 0,14 & 0,17 & 0,16 & 1,01 \\
\hline \multirow[t]{3}{*}{ Mínimo } & 2018 & 1,57 & 1,86 & 1,88 & 1,80 & 1,64 & 2,44 & 2485,54 \\
\hline & 2016 & 1,80 & 1,50 & 1,75 & 1,89 & 1,84 & 2,32 & 2355,70 \\
\hline & 2014 & 1,50 & 1,83 & 2,07 & 2,11 & 1,92 & 2,28 & 2010,23 \\
\hline \multirow[t]{3}{*}{ Máximo } & 2018 & 4,09 & 4,37 & 4,31 & 3,99 & 4,32 & 4,41 & 109452,96 \\
\hline & 2016 & 4,18 & 4,44 & 4,28 & 4,24 & 4,38 & 4,80 & 107638,21 \\
\hline & 2014 & 4,21 & 4,32 & 4,19 & 3,82 & 4,17 & 4,71 & 103721,75 \\
\hline \multirow[t]{3}{*}{$1^{\circ}$ Quartil } & 2018 & 2,42 & 2,43 & 2,54 & 2,69 & 2,61 & 3,10 & 5705,64 \\
\hline & 2016 & 2,39 & 2,44 & 2,56 & 2,60 & 2,62 & 3,06 & 5343,42 \\
\hline & 2014 & 2,47 & 2,54 & 2,72 & 2,77 & 2,69 & 3,05 & 5401,86 \\
\hline \multirow[t]{3}{*}{ Mediana } & 2018 & 2,73 & 2,90 & 2,96 & 2,99 & 3,07 & 3,46 & 11501,16 \\
\hline & 2016 & 2,83 & 2,99 & 3,01 & 3,07 & 3,16 & 3,51 & 11431,14 \\
\hline & 2014 & 2,93 & 2,94 & 3,02 & 3,12 & 3,15 & 3,51 & 11993,49 \\
\hline \multirow[t]{3}{*}{$3^{\circ}$ Quartil } & 2018 & 3,36 & 3,42 & 3,60 & 3,43 & 3,66 & 3,91 & 33801,23 \\
\hline & 2016 & 3,46 & 3,64 & 3,63 & 3,60 & 3,73 & 3,97 & 33516,43 \\
\hline & 2014 & 3,38 & 3,55 & 3,56 & 3,44 & 3,54 & 4,00 & 33189,01 \\
\hline
\end{tabular}

Nota: Alf (Alfândega); Inf (Infraestrutura); QCL (Qualidade e Comp. Logística); Cal (Carregamentos Internacionais); MoR (Monitoramento e Rastreabilidade); Pre (Previsibilidade); PIB (Produto Interno Bruto) per capita em dólar americano ajustado em relação a inflação para o ano base de 2010.

Fonte: Dados da pesquisa. 
$(2,89)$ em 2018 e menor mínima $(1,50)$ em 2014 juntamente com a Infraestrutura (Inf) em 2016.

Pode-se constatar, de modo geral, que as variáveis relacionadas às Regulações Políticas (Alf, Inf e QCL) apresentaram valores levemente inferiores às ligadas ao Desempenho na prestação de serviços (CaI, MoR e Pre). As primeiras apresentaram valores um pouco menores para os $1^{\circ}$ e $3^{\circ}$ quartis e para a mediana, demonstrando que as fatores institucionais ligados as regulações políticas apresentam desempenho inferior quando comparado as prestadoras de serviços logísticos.

As variáveis Qualidade e Competência Logística (QCL), Carregamentos Internacionais (CaI) e Monitoramento e Rastreabilidade (MoR) apresentaram valores intermediários na estatística descritiva, não exibindo nenhum valor individual relevante na análise em questão.

Adiante, a Tabela 2 apresenta a eficiência e posição no ranking anual dos 99 países para os três anos em estudo, além da variação da eficiência e da posição no ranking do ano de 2014 para 2018.

Quanto aos indicadores, entradas e saídas, não há problema que exista alto grau de correlação entre eles, de modo que formem agrupamentos dentro da amostra, todavia, não faz sentido considerar fatores que apresentem singularidade. Além disso, a omissão de variáveis fortemente correlacionadas pode ocasionar alterações significativas no resultado das medidas de eficiência (OLIVEIRA, 2018).

Analisando os pontos extremos para os anos de 2014, 2016 e 2018, verifica-se que a DMU mais eficiente foi o país Luxemburgo (assim como constatado por Mariano et al (2017) que relacionam as emissões de $\mathrm{CO} 2$ do setor de transporte com o LPI) nos três anos, acompanhado da Noruega que também alcançou a eficiência máxima no ano de 2016. Isso significa dizer que os dois países possuem a melhor combinação no uso de seus indicadores logísticos, quando comparado ao PIB per capta, sendo, portanto, $100 \%$ eficientes. Todos os demais são menos eficientes porque não estão utilizando sua estrutura logística de modo adequado, deixando assim a produção interna comprometida.

Esses países com eficiência logística máxima têm alguns pontos em comuns como sua localização geográfica no continente europeu, pequena extensão territorial e população relativamente pequena, além de excelentes indicadores de produção (PIB). Luxemburgo é um pequeno país situado na Europa Ocidental, sem saída para o mar e limitado pela Bélgica, França e Alemanha. Luxemburgo tem uma população de pouco mais de meio milhão de pessoas e uma área de aproximadamente $2586 \mathrm{~km}^{2}$. A Noruega está localizada na porção oeste da península Escandinava, banhada pelo oceano Atlântico e possui fronteiras terrestres com a Suécia, Finlândia e Rússia. Sua população está em torno de 5 milhões de habitantes que vive em uma extensão territorial de $323.895 \mathrm{~km}^{2}$ (CIA.GOV, 2020).

Todavia, não podemos admitir que países com pequena extensão territorial são mais propensos a possuírem melhor desempenho logístico, uma vez que muitos outros não foram considerados com eficiência logística superior ou se querem entraram no ranking dos 99 países mais eficientes. Além disso, tivemos países com grande extensão territorial ocupando as primeiras posições de eficiência logística, como os Estados Unidos, Canadá e Austrália.

Os piores países no ranking da eficiência logística foram a Papua Nova Guiné no ano de 2014, situada na Oceania e formada por um grupo de ilhas e arquipélagos, além do Egito com piores resultados em 2016 e 2018, localizado entre o nordeste da África e o sudoeste da Ásia. São países que não despontam no cenário econômico mundial e como visto nessa pesquisa, possuem sérios problemas ligados às suas regulações políticas e serviços referentes a logística.

Destaca-se também os países que mais subiram de posição no ranking de eficiência logística nesse período. A Irlanda foi o país que mais evoluiu subindo dez posições, saiu da 13a em 2014 para 3a em 2018 e melhorou $34,34 \%$ de sua eficiência logística, seguida pela República Dominicana que subiu 9 posições (de 72a em 2014 para 63 em 2018) com uma eficiência melhorada em 19,05\%. Em sentido contrário, a República do Congo foi o país com pior variação de eficiência logística do ano de 2014 para 2018, caindo da $78^{a}$ para $95^{\mathrm{a}}$ e reduzindo $39,07 \%$ de sua eficiência. O Equador também piorou significativamente seu desempenho ao perder $18,56 \%$ de sua eficiência e cair dez posições no ranking.

No que concerne ao Brasil, embora o país tenha melhorado nove posições no ranking geral do LPI, subindo da $65^{\mathrm{a}}$ posição em 2014 para 56a em 2018 (BANCO MUNDIAL, 2018), o país piorou sua efi- 
Tabela 2 Eficiência anual e posição no ranking para os países em análise.

\begin{tabular}{|c|c|c|c|c|c|c|c|c|}
\hline \multirow{2}{*}{ País } & \multicolumn{2}{|c|}{2014} & \multicolumn{2}{|c|}{2016} & \multicolumn{2}{|c|}{2018} & \multirow{2}{*}{$\begin{array}{c}\text { Variação } \\
\text { Eficiência } \\
\text { 2014-2018 }\end{array}$} & \multirow{2}{*}{$\begin{array}{c}\text { Variação } \\
\text { Posição } \\
\text { 2014-2018 }\end{array}$} \\
\hline & $\begin{array}{c}\text { Eficiência } \\
\%\end{array}$ & Posição & $\begin{array}{c}\text { Eficiência } \\
\%\end{array}$ & Posição & $\begin{array}{c}\text { Eficiência } \\
\%\end{array}$ & Posição & & \\
\hline Algeria & 6,91 & $79^{\circ}$ & 7,30 & $83^{\circ}$ & 7,26 & $74^{\circ}$ & $5,11 \%$ & 5 \\
\hline Angola & 6,78 & $81^{\circ}$ & 7,55 & $80^{\circ}$ & 7,00 & 770 & $3,26 \%$ & 4 \\
\hline Argentina & 15,58 & $54^{\circ}$ & 15,08 & $54^{\circ}$ & 13,87 & $55^{\circ}$ & $-10,98 \%$ & -1 \\
\hline Armenia & 5,87 & 870 & 7,43 & $82^{\circ}$ & 5,77 & 870 & $-1,69 \%$ & 0 \\
\hline Australia & 61,45 & $6^{\circ}$ & 60,03 & 70 & 53,14 & $8^{\circ}$ & $-13,52 \%$ & -2 \\
\hline Austria & 54,12 & $12^{\circ}$ & 48,90 & $16^{\circ}$ & 42,69 & $14^{\circ}$ & $-21,11 \%$ & -2 \\
\hline Bahamas, The & 39,40 & $25^{\circ}$ & 41,15 & $24^{\circ}$ & 41,03 & $19^{\circ}$ & $4,15 \%$ & 6 \\
\hline Bahrain & 35,36 & $29^{\circ}$ & 28,51 & $34^{\circ}$ & 26,98 & $32^{\circ}$ & $-23,71 \%$ & -3 \\
\hline Belarus & 9,99 & 670 & 12,28 & $64^{\circ}$ & 8,97 & $69^{\circ}$ & $-10,18 \%$ & -2 \\
\hline Belgium & 45,88 & $19^{\circ}$ & 45,25 & $19^{\circ}$ & 41,13 & $18^{\circ}$ & $-10,35 \%$ & 1 \\
\hline Bhutan & 5,15 & $90^{\circ}$ & 5,72 & $88^{\circ}$ & 5,45 & $88^{\circ}$ & $5,85 \%$ & 2 \\
\hline Bolivia & 3,84 & $96^{\circ}$ & 4,63 & $93^{\circ}$ & 3,87 & 970 & $0,71 \%$ & -1 \\
\hline Bosnia and Herz. & 7,60 & $76^{\circ}$ & 9,25 & $70^{\circ}$ & 7,91 & $73^{\circ}$ & $4,12 \%$ & 3 \\
\hline Brazil & 17,81 & $48^{\circ}$ & 15,53 & $52^{\circ}$ & 14,71 & $52^{\circ}$ & $-17,43 \%$ & -4 \\
\hline Bulgaria & 9,56 & $68^{\circ}$ & 12,76 & $61^{\circ}$ & 10,01 & $66^{\circ}$ & $4,74 \%$ & 2 \\
\hline Canada & 53,67 & $14^{\circ}$ & 55,71 & 90 & 46,59 & $12^{\circ}$ & $-13,18 \%$ & 2 \\
\hline Chile & 18,29 & $46^{\circ}$ & 20,94 & $41^{\circ}$ & 16,19 & $49^{\circ}$ & $-11,51 \%$ & -3 \\
\hline China & 6,70 & $82^{\circ}$ & 7,28 & $84^{\circ}$ & 7,16 & $75^{\circ}$ & $6,91 \%$ & 7 \\
\hline Colombia & 11,36 & $62^{\circ}$ & 12,41 & $63^{\circ}$ & 9,46 & 670 & $-16,72 \%$ & -5 \\
\hline Congo, Rep. & 7,08 & $78^{\circ}$ & 5,45 & $91^{\circ}$ & 4,32 & $95^{\circ}$ & $-39,07 \%$ & -17 \\
\hline Costa Rica & 13,63 & $56^{\circ}$ & 15,65 & $51^{\circ}$ & 12,96 & $58^{\circ}$ & $-4,89 \%$ & -2 \\
\hline Croatia & 18,35 & $45^{\circ}$ & 18,59 & $44^{\circ}$ & 17,01 & $46^{\circ}$ & $-7,32 \%$ & -1 \\
\hline Cyprus & 37,37 & $28^{\circ}$ & 42,00 & $22^{\circ}$ & 34,54 & $25^{\circ}$ & $-7,58 \%$ & 3 \\
\hline Czech Republic & 24,14 & $39^{\circ}$ & 25,07 & 370 & 22,31 & $38^{\circ}$ & $-7,59 \%$ & 1 \\
\hline Denmark & 62,08 & $5^{\circ}$ & 66,78 & $5^{\circ}$ & 54,72 & 70 & $-11,86 \%$ & -2 \\
\hline Dominican Rep. & 8,60 & $72^{\circ}$ & 11,46 & $66^{\circ}$ & 10,24 & $63^{\circ}$ & $19,05 \%$ & 9 \\
\hline Ecuador & 7,99 & $73^{\circ}$ & 8,50 & $72^{\circ}$ & 6,50 & $83^{\circ}$ & $-18,56 \%$ & -10 \\
\hline Egypt, Arab Rep. & 4,00 & $95^{\circ}$ & 3,56 & $98^{\circ}$ & 3,49 & $99^{\circ}$ & $-12,58 \%$ & -4 \\
\hline El Salvador & 5,31 & $89^{\circ}$ & 5,80 & 870 & 5,07 & $89^{\circ}$ & $-4,36 \%$ & 0 \\
\hline Equatorial Guinea & 29,92 & $32^{\circ}$ & 36,98 & $26^{\circ}$ & 19,99 & $41^{\circ}$ & $-33,20 \%$ & -9 \\
\hline Estonia & 21,45 & $41^{\circ}$ & 22,61 & $39^{\circ}$ & 20,83 & $39^{\circ}$ & $-2,90 \%$ & 2 \\
\hline Fiji & 6,50 & $85^{\circ}$ & 7,77 & $78^{\circ}$ & 6,94 & $78^{\circ}$ & $6,75 \%$ & 7 \\
\hline Finland & 54,86 & $11^{\circ}$ & 51,24 & $14^{\circ}$ & 42,42 & $15^{\circ}$ & $-22,68 \%$ & -4 \\
\hline France & 44,96 & $20^{\circ}$ & 45,20 & $20^{\circ}$ & 38,63 & $20^{\circ}$ & $-14,07 \%$ & 0 \\
\hline
\end{tabular}


Tabela 2 Eficiência anual e posição no ranking para os países em análise.

\begin{tabular}{|c|c|c|c|c|c|c|c|c|}
\hline \multirow{2}{*}{ País } & \multicolumn{2}{|c|}{2014} & \multicolumn{2}{|c|}{2016} & \multicolumn{2}{|c|}{2018} & \multirow{2}{*}{$\begin{array}{c}\text { Variação } \\
\text { Eficiência } \\
\text { 2014-2018 }\end{array}$} & \multirow{2}{*}{$\begin{array}{c}\text { Variação } \\
\text { Posição } \\
\text { 2014-2018 }\end{array}$} \\
\hline & $\begin{array}{c}\text { Eficiência } \\
\%\end{array}$ & Posição & $\begin{array}{c}\text { Eficiência } \\
\%\end{array}$ & Posição & $\begin{array}{c}\text { Eficiência } \\
\%\end{array}$ & Posição & & \\
\hline Gabon & 18,50 & $44^{\circ}$ & 18,28 & $45^{\circ}$ & 15,27 & $51^{\circ}$ & $-17,42 \%$ & -7 \\
\hline Georgia & 6,50 & $84^{\circ}$ & 7,60 & $79^{\circ}$ & 6,85 & $81^{\circ}$ & $5,48 \%$ & 3 \\
\hline Germany & 45,97 & $18^{\circ}$ & 46,25 & $18^{\circ}$ & 38,08 & $21^{\circ}$ & $-17,17 \%$ & -3 \\
\hline Greece & 28,87 & $33^{\circ}$ & 29,99 & $32^{\circ}$ & 26,18 & $33^{\circ}$ & $-9,32 \%$ & 0 \\
\hline Guatemala & 4,38 & $94^{\circ}$ & 5,50 & $90^{\circ}$ & 4,77 & $91^{\circ}$ & $9,01 \%$ & 3 \\
\hline Guyana & 5,77 & $88^{\circ}$ & 6,49 & $86^{\circ}$ & 6,12 & $86^{\circ}$ & $5,97 \%$ & 2 \\
\hline Hong Kong SAR & 39,15 & $26^{\circ}$ & 36,65 & $28^{\circ}$ & 33,18 & $28^{\circ}$ & $-15,26 \%$ & -2 \\
\hline Hungary & 16,81 & $49^{\circ}$ & 17,69 & $47^{\circ}$ & 16,92 & 470 & $0,63 \%$ & 2 \\
\hline Iceland & 58,76 & 70 & 61,83 & $6^{\circ}$ & 59,71 & $6^{\circ}$ & $1,61 \%$ & 1 \\
\hline Indonesia & 4,60 & $92^{\circ}$ & 5,68 & $89^{\circ}$ & 4,98 & $90^{\circ}$ & $8,19 \%$ & 2 \\
\hline Iraq & 10,25 & $66^{\circ}$ & 11,16 & $67^{\circ}$ & 10,14 & $64^{\circ}$ & $-1,03 \%$ & 2 \\
\hline Ireland & 53,84 & $13^{\circ}$ & 71,97 & $4^{\circ}$ & 72,33 & $3^{\circ}$ & $34,34 \%$ & 10 \\
\hline Israel & 44,03 & $21^{\circ}$ & 38,54 & $25^{\circ}$ & 37,93 & $22^{\circ}$ & $-13,87 \%$ & -1 \\
\hline Italy & 38,10 & 270 & 36,88 & $27^{\circ}$ & 32,94 & $29^{\circ}$ & $-13,53 \%$ & -2 \\
\hline Jamaica & 6,80 & $80^{\circ}$ & 8,34 & $74^{\circ}$ & 6,84 & $82^{\circ}$ & $0,67 \%$ & -2 \\
\hline Japan & 49,53 & 170 & 50,28 & $15^{\circ}$ & 41,54 & $16^{\circ}$ & $-16,13 \%$ & 1 \\
\hline Jordan & 4,96 & $91^{\circ}$ & 4,70 & $92^{\circ}$ & 4,40 & $94^{\circ}$ & $-11,33 \%$ & -3 \\
\hline Kazakhstan & 16,42 & $52^{\circ}$ & 15,44 & $53^{\circ}$ & 14,47 & $53^{\circ}$ & $-11,89 \%$ & -1 \\
\hline Korea, Rep. & 26,89 & $36^{\circ}$ & 27,40 & $36^{\circ}$ & 25,02 & $35^{\circ}$ & $-6,93 \%$ & 1 \\
\hline Kuwait & 52,98 & $15^{\circ}$ & 48,52 & $17^{\circ}$ & 41,36 & 170 & $-21,93 \%$ & -2 \\
\hline Latvia & 16,66 & $51^{\circ}$ & 17,59 & $48^{\circ}$ & 19,70 & $43^{\circ}$ & $18,24 \%$ & 8 \\
\hline Lebanon & 11,11 & $63^{\circ}$ & 9,89 & $68^{\circ}$ & 8,72 & $70^{\circ}$ & $-21,52 \%$ & -7 \\
\hline Libya & 14,24 & $55^{\circ}$ & 12,21 & $65^{\circ}$ & 14,25 & $54^{\circ}$ & $0,08 \%$ & 1 \\
\hline Lithuania & 18,00 & 470 & 17,32 & $49^{\circ}$ & 20,47 & $40^{\circ}$ & $13,72 \%$ & 7 \\
\hline Luxembourg & 100,00 & $1^{\circ}$ & 100,00 & $1^{\circ}$ & 100,00 & $1^{\circ}$ & $0,00 \%$ & 0 \\
\hline Macedonia, FYR & 7,68 & $75^{\circ}$ & 8,42 & $73^{\circ}$ & 7,06 & $76^{\circ}$ & $-8,07 \%$ & -1 \\
\hline Malaysia & 11,66 & $61^{\circ}$ & 13,01 & $60^{\circ}$ & 13,04 & $57^{\circ}$ & $11,91 \%$ & 4 \\
\hline Maldives & 13,45 & 570 & 12,63 & $62^{\circ}$ & 11,71 & $61^{\circ}$ & $-12,94 \%$ & -4 \\
\hline Malta & 32,26 & $31^{\circ}$ & 34,57 & $29^{\circ}$ & 33,95 & $26^{\circ}$ & $5,24 \%$ & 5 \\
\hline Mexico & 13,27 & $58^{\circ}$ & 13,68 & $58^{\circ}$ & 11,99 & $60^{\circ}$ & $-9,63 \%$ & -2 \\
\hline Moldova & 3,53 & $98^{\circ}$ & 3,95 & $97^{\circ}$ & 4,23 & $96^{\circ}$ & $19,83 \%$ & 2 \\
\hline Mongolia & 6,64 & $83^{\circ}$ & 7,49 & $81^{\circ}$ & 6,31 & $85^{\circ}$ & $-4,90 \%$ & -2 \\
\hline Montenegro & 10,31 & $65^{\circ}$ & 13,85 & $57^{\circ}$ & 10,12 & $65^{\circ}$ & $-1,76 \%$ & 0 \\
\hline Netherlands & 52,91 & $16^{\circ}$ & 52,01 & $13^{\circ}$ & 45,31 & $13^{\circ}$ & $-14,37 \%$ & 3 \\
\hline
\end{tabular}


Tabela 2 Eficiência anual e posição no ranking para os países em análise.

\begin{tabular}{|c|c|c|c|c|c|c|c|c|}
\hline \multirow{2}{*}{ País } & \multicolumn{2}{|c|}{2014} & \multicolumn{2}{|c|}{2016} & \multicolumn{2}{|c|}{2018} & \multirow{2}{*}{$\begin{array}{c}\text { Variação } \\
\text { Eficiência } \\
\text { 2014-2018 }\end{array}$} & \multirow{2}{*}{$\begin{array}{l}\text { Variação } \\
\text { Posição } \\
\text { 2014-2018 }\end{array}$} \\
\hline & $\begin{array}{c}\text { Eficiência } \\
\%\end{array}$ & Posição & $\begin{array}{c}\text { Eficiência } \\
\%\end{array}$ & Posição & $\begin{array}{c}\text { Eficiência } \\
\%\end{array}$ & Posição & & \\
\hline New Zealand & 43,22 & $22^{\circ}$ & 52,29 & $12^{\circ}$ & 33,82 & 270 & $-21,75 \%$ & -5 \\
\hline Norway & 95,24 & $2^{\circ}$ & 100,00 & $1^{\circ}$ & 85,23 & $2^{\circ}$ & $-10,52 \%$ & 0 \\
\hline Oman & 24,62 & $38^{\circ}$ & 21,91 & $40^{\circ}$ & 18,10 & $44^{\circ}$ & $-26,48 \%$ & -6 \\
\hline Panama & 12,73 & $59^{\circ}$ & 13,97 & $55^{\circ}$ & 12,92 & $59^{\circ}$ & $1,50 \%$ & 0 \\
\hline Papua New G. & 3,40 & $99^{\circ}$ & 4,08 & $95^{\circ}$ & 4,54 & $92^{\circ}$ & $33,65 \%$ & 7 \\
\hline Paraguay & 7,20 & $77^{\circ}$ & 8,23 & $76^{\circ}$ & 6,86 & $80^{\circ}$ & $-4,78 \%$ & -3 \\
\hline Peru & 8,83 & $71^{\circ}$ & 9,19 & $71^{\circ}$ & 9,18 & $68^{\circ}$ & $4,07 \%$ & 3 \\
\hline Philippines & 3,54 & 970 & 4,02 & $96^{\circ}$ & 3,68 & $98^{\circ}$ & $4,00 \%$ & -1 \\
\hline Poland & 16,69 & $50^{\circ}$ & 18,20 & $46^{\circ}$ & 16,37 & $48^{\circ}$ & $-1,88 \%$ & 2 \\
\hline Portugal & 24,94 & 370 & 28,07 & $35^{\circ}$ & 23,86 & $36^{\circ}$ & $-4,34 \%$ & 1 \\
\hline Qatar & 77,87 & $4^{\circ}$ & 74,41 & $3^{\circ}$ & 68,41 & $5^{\circ}$ & $-12,15 \%$ & -1 \\
\hline Romania & 12,20 & $60^{\circ}$ & 13,39 & $59^{\circ}$ & 13,79 & $56^{\circ}$ & $13,00 \%$ & 4 \\
\hline Russian Fed. & 19,59 & $43^{\circ}$ & 20,34 & $42^{\circ}$ & 15,29 & $50^{\circ}$ & $-21,96 \%$ & -7 \\
\hline Saudi Arabia & 26,95 & $35^{\circ}$ & 28,82 & $33^{\circ}$ & 25,09 & $34^{\circ}$ & $-6,91 \%$ & 1 \\
\hline Serbia & 9,46 & $69^{\circ}$ & 9,74 & $69^{\circ}$ & 8,37 & $71^{\circ}$ & $-11,53 \%$ & -2 \\
\hline Singapore & 55,21 & 90 & 53,85 & $11^{\circ}$ & 48,80 & $10^{\circ}$ & $-11,61 \%$ & -1 \\
\hline Slovak Republic & 22,40 & $40^{\circ}$ & 23,18 & $38^{\circ}$ & 22,92 & 370 & $2,32 \%$ & 3 \\
\hline Slovenia & 27,44 & $34^{\circ}$ & 30,36 & $31^{\circ}$ & 28,97 & $31^{\circ}$ & $5,59 \%$ & 3 \\
\hline South Africa & 8,96 & $70^{\circ}$ & 8,26 & $75^{\circ}$ & 8,05 & $72^{\circ}$ & $-10,12 \%$ & -2 \\
\hline Spain & 32,26 & $30^{\circ}$ & 33,44 & $30^{\circ}$ & 29,18 & $30^{\circ}$ & $-9,52 \%$ & 0 \\
\hline Sweden & 56,93 & $8^{\circ}$ & 55,53 & $10^{\circ}$ & 49,52 & 90 & $-13,03 \%$ & -1 \\
\hline Switzerland & 84,44 & 30 & 81,72 & $2^{\circ}$ & 69,02 & $4^{\circ}$ & $-18,27 \%$ & -1 \\
\hline Thailand & 6,38 & $86^{\circ}$ & 7,25 & $85^{\circ}$ & 6,47 & $84^{\circ}$ & $1,50 \%$ & 2 \\
\hline Tunisia & 7,69 & $74^{\circ}$ & 7,96 & 770 & 6,86 & $79^{\circ}$ & $-10,84 \%$ & -5 \\
\hline Turkey & 15,85 & $53^{\circ}$ & 16,20 & $50^{\circ}$ & 17,70 & $45^{\circ}$ & $11,71 \%$ & 8 \\
\hline Turkmenistan & 10,95 & $64^{\circ}$ & 13,93 & $56^{\circ}$ & 10,88 & $62^{\circ}$ & $-0,64 \%$ & 2 \\
\hline Ukraine & 4,50 & $93^{\circ}$ & 4,48 & $94^{\circ}$ & 4,47 & $93^{\circ}$ & $-0,48 \%$ & 0 \\
\hline United Arab Emir. & 42,84 & $23^{\circ}$ & 41,91 & $23^{\circ}$ & 36,16 & $24^{\circ}$ & $-15,59 \%$ & -1 \\
\hline United Kingdom & 42,60 & $24^{\circ}$ & 43,89 & $21^{\circ}$ & 36,79 & $23^{\circ}$ & $-13,63 \%$ & 1 \\
\hline United States & 55,02 & $10^{\circ}$ & 56,23 & $8^{\circ}$ & 47,36 & $11^{\circ}$ & $-13,92 \%$ & -1 \\
\hline Uruguay & 20,87 & $42^{\circ}$ & 19,68 & $43^{\circ}$ & 19,70 & $42^{\circ}$ & $-5,57 \%$ & 0 \\
\hline
\end{tabular}

Fonte: Dados da pesquisa. 
ciência logística em 17,43\% e caiu quatro posições no ranking de eficiência logística nesse período em questão. Tal fato demonstra que embora o país tenha melhorado seu desempenho logístico, esta questão não contribuiu para o aumento da eficiência logística.

Para determinar níveis de eficiência para os países, foi utilizado a média dos índices de eficiência dos três anos em análise $(24,60)$ mais ou menos a metade do desvio padrão $(10,59)$, sendo criado três limites conforme apresentados na Tabela 3. Aplicou-se a média da eficiência dos três anos para evitar que um fato isolado que aconteceu em uma determinada data e região, alterasse o índice de um país para mais ou para menos e inviabilize a análise.

Embora apenas dois países apresentaram-se com eficiência máxima (Luxemburgo e Noruega), constata-se por meio das faixas de eficiência que 28 foram classificados com nível de eficiência superior aos demais, 26 países com nível de eficiência mediano e 45 com nível inferior e que demandam uma atenção especial no setor logístico. E para uma melhor com-
Tabela 3 Níveis de eficiência logística dos países.

\begin{tabular}{c|c|c}
\hline $\begin{array}{c}\text { Nível de } \\
\text { eficiência média }\end{array}$ & $\begin{array}{c}\text { Limites de } \\
\text { eficiência }\end{array}$ & no de países \\
\hline Superior & $\theta>35,71$ & 28 \\
\hline Mediano & $35,71 \geq \theta \geq 14,53$ & 26 \\
\hline Inferior & $\theta<14,53$ & 45 \\
\hline
\end{tabular}

Fonte: Elaborado pelo autor.

preensão da distribuição dos países no mapa global, a Figura 1 apresenta as localizações geográficas desses 99 países mais eficientes. As cores estão distribuídas em tons de laranja, sendo as mais claras pertencentes aos países menos eficientes, e à medida que o tom da cor escurece, indica um aumento na eficiência dos países. Na cor cinza são os excluídos da amostra.

Para testar se esses grupos de eficiência média são, de fato, diferentes, desenvolveu-se a seguir uma estatística multivariada nesse intuito e com o objetivo de analisar se há um indicador LPI mais expressivo no que tange a eficiência logística dos países.

Figura 1 Localização geográfica dos países com melhor eficiência logística (2014-2018).

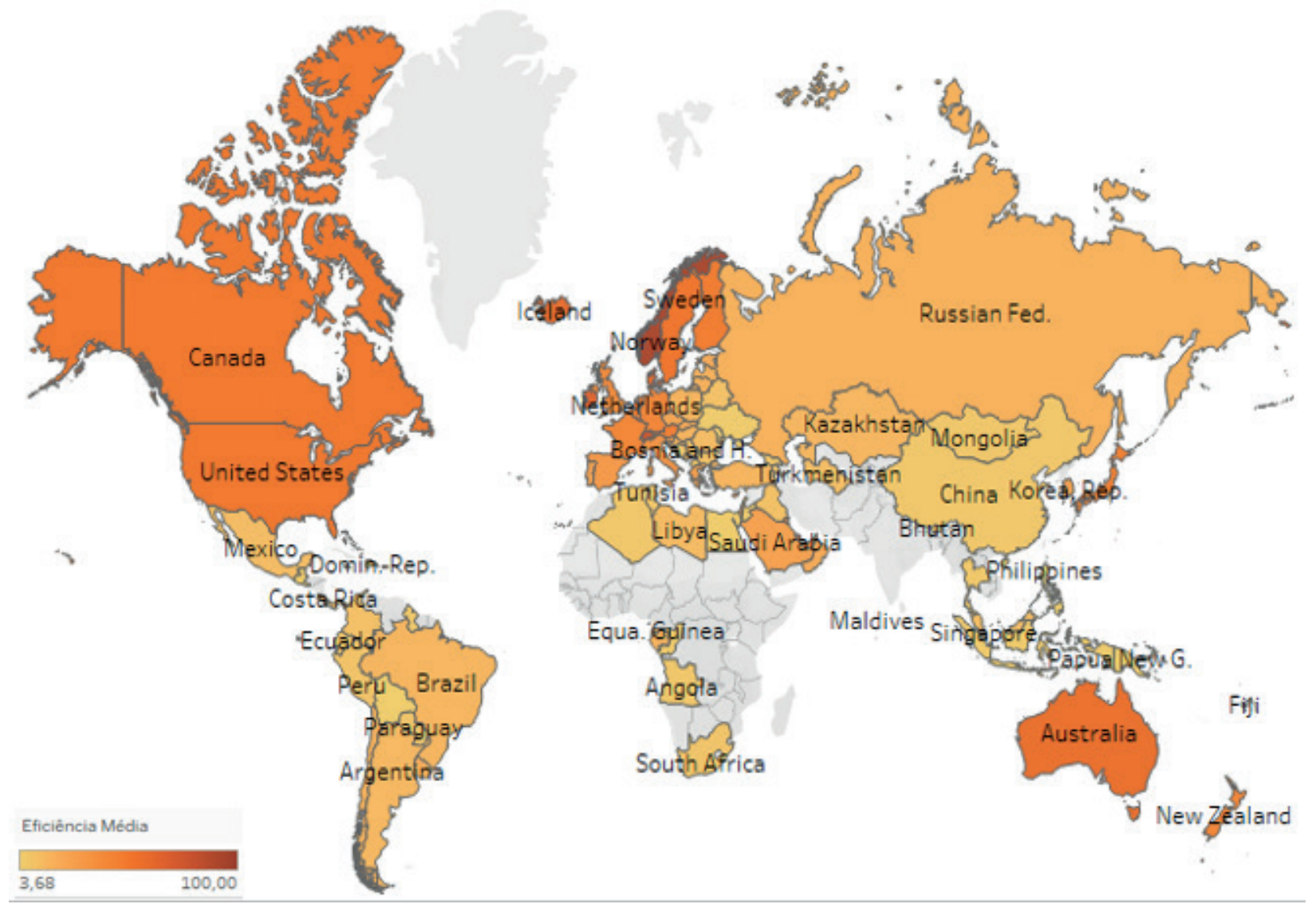

Fonte: Elaborado pelo autor utilizando o software Tableu. 


\subsection{Análise dos indicadores LPI por grupos de nível de eficiência}

Inicialmente busca-se compreender melhor as características da amostra utilizada. A amostra foi dividida em três grupos: países com eficiência média inferior (1), países com eficiência média mediana (2) e países com eficiência média superior (3). Além de descrever a amostra como um todo, objetivou-se dar ênfase às características individuais de cada grupo, sendo esse ponto o mais relevante na presente análise.
Na Tabela 4 apresenta-se a estatística descritiva para a amostra total por variável e por grupo (eficiência inferior $=1$, eficiência mediana $=2$ e eficiência superior $=3$ ), assim como os valores Assimetria e Curtose para cada indicador individualmente. Os valores de significância, apresentados para Assimetria e Curtose, foram obtidos baseados nos valores padronizados, por meio dos scores- $\mathrm{Z}$, ao subtrair a média da distribuição e dividindo o resultado pelo desvio padrão da distribuição, sendo convertidos em scores-z da mesma forma para assimetria e curtose

Tabela 4 Estatística Descritiva dos Indicadores separados por grupos.

\begin{tabular}{|c|c|c|c|c|c|c|c|c|c|c|c|}
\hline \multirow{2}{*}{\multicolumn{2}{|c|}{ Descritivos }} & \multirow{2}{*}{$\mathbf{N}$} & \multirow{2}{*}{ Média } & \multirow{2}{*}{$\begin{array}{l}\text { Desvio } \\
\text { Padrão }\end{array}$} & \multirow{2}{*}{$\begin{array}{c}\text { Erro } \\
\text { Padrão }\end{array}$} & \multirow{2}{*}{ Mín. } & \multirow{2}{*}{ Máx. } & \multicolumn{2}{|c|}{ Assimetria } & \multicolumn{2}{|c|}{ Curtose } \\
\hline & & & & & & & & Estatística & Sig. & Estatística & Sig. \\
\hline \multirow[t]{4}{*}{ Alfândega } & 1 & 45 & 2,510 & 0,323 & 0,048 & 1,910 & 3,290 & 0,571 & & 0,605 & \\
\hline & 2 & 26 & 2,912 & 0,419 & 0,082 & 2,010 & 3,580 & $-0,693$ & & $-0,135$ & \\
\hline & 3 & 28 & 3,624 & 0,356 & 0,067 & 2,750 & 4,100 & $-1,197$ & & 0,798 & \\
\hline & Total & 99 & 2,931 & 0,587 & 0,059 & 1,910 & 4,100 & 0,275 & 0,001 & $-1,035$ & 0,001 \\
\hline \multirow[t]{4}{*}{ Infraestrutura } & 1 & 45 & 2,537 & 0,378 & 0,056 & 2,020 & 3,720 & 1,245 & & 1,625 & \\
\hline & 2 & 26 & 3,035 & 0,435 & 0,085 & 1,830 & 3,780 & $-1,037$ & & 1,905 & \\
\hline & 3 & 28 & 3,809 & 0,433 & 0,082 & 2,620 & 4,380 & $-1,323$ & & 1,149 & \\
\hline & Total & 99 & 3,027 & 0,670 & 0,067 & 1,830 & 4,380 & 0,309 & 0,001 & $-1,071$ & 0,001 \\
\hline \multirow{4}{*}{$\begin{array}{l}\text { Qualidade e } \\
\text { Competência } \\
\text { Logística }\end{array}$} & 1 & 45 & 2,652 & 0,369 & 0,055 & 2,010 & 3,560 & 0,680 & & 0,160 & \\
\hline & 2 & 26 & 3,079 & 0,403 & 0,079 & 2,070 & 3,790 & $-0,759$ & & 1,217 & \\
\hline & 3 & 28 & 3,745 & 0,392 & 0,074 & 2,640 & 4,240 & $-1,599$ & & 2,230 & \\
\hline & Total & 99 & 3,074 & 0,596 & 0,060 & 2,010 & 4,240 & 0,189 & 0,001 & $-1,088$ & 0,001 \\
\hline \multirow{4}{*}{$\begin{array}{l}\text { Carregamentos } \\
\text { Internacionais }\end{array}$} & 1 & 45 & 2,763 & 0,356 & 0,053 & 2,230 & 3,580 & 0,683 & & $-0,239$ & \\
\hline & 2 & 26 & 3,096 & 0,358 & 0,070 & 2,290 & 3,660 & $-0,614$ & & 0,236 & \\
\hline & 3 & 28 & 3,519 & 0,304 & 0,057 & 2,750 & 3,950 & $-1,082$ & & 0,510 & \\
\hline & Total & 99 & 3,064 & 0,465 & 0,047 & 2,230 & 3,950 & $-0,050$ & 0,001 & $-1,140$ & 0,001 \\
\hline \multirow{4}{*}{$\begin{array}{l}\text { Monitoramento e } \\
\text { Rastreabilidade }\end{array}$} & 1 & 45 & 2,716 & 0,383 & 0,057 & 2,110 & 3,610 & 0,561 & & $-0,421$ & \\
\hline & 2 & 26 & 3,176 & 0,427 & 0,084 & 2,020 & 3,740 & $-1,083$ & & 1,626 & \\
\hline & 3 & 28 & 3,780 & 0,398 & 0,075 & 2,600 & 4,220 & $-1,627$ & & 2,338 & \\
\hline & Total & 99 & 3,138 & 0,597 & 0,060 & 2,020 & 4,220 & 0,720 & 0,001 & $-1,104$ & 0,001 \\
\hline \multirow[t]{4}{*}{ Previsibiliade } & 1 & 45 & 3,128 & 0,353 & 0,053 & 2,490 & 3,880 & 0,443 & & $-0,485$ & \\
\hline & 2 & 26 & 3,533 & 0,389 & 0,076 & 2,500 & 4,050 & $-1,033$ & & 1,180 & \\
\hline & 3 & 28 & 4,064 & 0,329 & 0,062 & 2,960 & 4,470 & $-1,751$ & & 3,850 & \\
\hline & Total & 99 & 3,499 & 0,528 & 0,053 & 2,490 & 4,470 & $-0,110$ & 0,001 & $-1,084$ & 0,001 \\
\hline
\end{tabular}

Fonte: Dados da pesquisa 


$$
\text { (Ex. } Z_{\text {Assimetria }}=\frac{S-\bar{X}}{\sigma_{\text {Assimetria }}} \text { e } Z_{\text {Curtose }}=\frac{K-\bar{X}}{\sigma_{\text {Curtose }}} \text { ). }
$$

Os valores da significância são definidos ao se observar os valores padronizados como valores absolutos, ou seja, $|x|>1,96$ é significativo a $p>0,05$, $|x|>2,58$ é significativo a $p>0,01 \mathrm{e}|x|>3,29$ é significativo a $p>0,001)$. Amostras grandes fornecerão erros padrão pequenos (FIELD, 2013).

Dentre as considerações a serem feitas por meio da Tabela 4, observa-se inicialmente que as medidas entre os grupos são diferentes entre eles para todos os indicadores LPI. Como era de se esperar, os valores da média, mínima e máxima são maiores nos grupos $3 \mathrm{e}$ 2 , nessa ordem, sendo a única exceção o valor mínimo do indicador Monitoramento e Rastreabilidade $(2,020)$ que se encontra no grupo 2 .

Destaca-se também que os níveis de significância para Assimetria (repartição dos valores em torno da média) e Curtose (menor ou maior grau de "achatamento" da Distribuição ou Curva de Frequência) apresentaram valores satisfatórios para todos os valores da amostra.

Para verificar se os indicadores apresentam diferenças estatísticas significativas para discriminar os grupos de eficiência inferior, mediana e superior, foi realizado o Teste ANOVA de um fator (One-Way) para comparar as médias individuais dos grupos e verificar o poder de discriminação de cada indicador do LPI.

Um dos pressupostos da ANOVA é a hipótese nula de homogeneidade de variância (grupos têm variâncias iguais), que pode ser medida por meio do teste de Levene, que apresenta valores não significativos (Sig. > 0,05) para validar a igualdade de variâncias dos grupos. A vantagem deste teste em relação aos demais testes similares é que ele é menos sensível aos desvios de normalidade, além de ser considerado um teste mais robusto (FÁVERO; BELFIORE, 2017).

Como pode ser observado na Tabela 5, a estatística de Levene, que verifica se há alguma diferença significativa entre as variâncias dos grupos, apresenta um resultado não significativo para todas as variáveis, sendo esse um indicativo de que a hipótese foi satisfeita.

Esse resultado vai de encontro ao trabalho de Martí, Puertas e García (2014) que concluíram que
Tabela 5 Teste de Homogeneidade de Variâncias.

\begin{tabular}{l|c|c|c|c}
\hline & $\begin{array}{c}\text { Estatística } \\
\text { de Levene }\end{array}$ & df1 & df2 & Sig. \\
\hline Alfândega & 1,774 & 2 & 96 & 0,175 \\
\hline $\begin{array}{l}\text { Infraestrutura } \\
\begin{array}{l}\text { Qualidade e } \\
\text { Competência Logística }\end{array}\end{array}$ & 0,325 & 2 & 96 & 0,723 \\
\hline $\begin{array}{l}\text { Carregamentos } \\
\text { Internacionais }\end{array}$ & 0,66 & 2 & 96 & 0,519 \\
\hline $\begin{array}{l}\text { Monitoramento e } \\
\text { Rastreabilidade }\end{array}$ & 0,071 & 2 & 96 & 0,932 \\
\hline Previsibiliade & 0,701 & 2 & 96 & 0,499 \\
\hline
\end{tabular}

Legenda: $d f$ - grau de liberdade.

Fonte: Dados da pesquisa.

todos indicadores do LPI colaboram para o crescimento significativo dos fluxos de comércio.

Diante desse fato aplicou-se o teste ANOVA com três grupos para verificar se há diferenças significativas nas variâncias de cada grupo, examinando se esses são similares e se há influência de alguma variável nos grupos. A Tabela 6 apresenta a ANOVA de um fator para os grupos em questão.

Como pode ser visto na Tabela 6, todas as variáveis apresentaram significância estatística a $1 \%$. $\mathrm{O}$ teste $\mathrm{F}$ da ANOVA indica que há diferença entre os grupos, isto é, os indicadores possuem médias diferentes entre os grupos e isso possibilita, estatisticamente, criar regras para identificar países com eficiência média inferior, mediana e superior.

Dando prosseguimento no estudo, desenvolveu-se a análise discriminante para a criação dos scores na tentativa de elucidar quais variáveis (indicadores) mais discriminam os grupos. Para essa análise, são considerados indicadores significantes aqueles que apresentam significância menor ou igual a 0,05 (sig. < 0,05). Sendo assim, com base na observação da Tabela 7, pode-se concluir que os seis indicadores têm poder individual para discriminar os grupos e podem ser utilizados na análise.

Outro dado presente na Tabela 7 é o Lambda de Wilks. Quanto menor for esse valor, juntamente com seu nível de significância, melhor será o poder estatístico dessa variável de discriminação entre os grupos (HAIR et al., 2009). Uma vez que todos foram significativos, pelo Lambda de Wilks observa-se que 
Tabela 6 ANOVA de um fator para os grupos de Eficiência Média.

\begin{tabular}{|c|c|c|c|c|c|c|}
\hline & & $\begin{array}{l}\text { Soma dos } \\
\text { Quadrados }\end{array}$ & df & $\begin{array}{l}\text { Quadrado } \\
\text { Médio }\end{array}$ & $\mathbf{F}$ & Sig. \\
\hline \multirow[t]{3}{*}{ Alfândega } & Entre Grupos & 21,442 & 2 & 10,721 & 83,142 &, 000 \\
\hline & Nos grupos & 12,379 & 96 & 0,129 & & \\
\hline & Total & 33,820 & 98 & & & \\
\hline \multirow[t]{3}{*}{ Infraestrutura } & Entre Grupos & 27,935 & 2 & 13,968 & 83,441 &, 000 \\
\hline & Nos grupos & 16,070 & 96 & 0,167 & & \\
\hline & Total & 44,005 & 98 & & & \\
\hline \multirow[t]{3}{*}{ Qualidade e Competência Logística } & Entre Grupos & 20,610 & 2 & 10,305 & 69,707 &, 000 \\
\hline & Nos grupos & 14,192 & 96 & 0,148 & & \\
\hline & Total & 34,801 & 98 & & & \\
\hline \multirow[t]{3}{*}{ Carregamentos Internacionais } & Entre Grupos & 9,909 & 2 & 4,955 & 42,169 &, 000 \\
\hline & Nos grupos & 11,279 & 96 & 0,117 & & \\
\hline & Total & 21,188 & 98 & & & \\
\hline \multirow[t]{3}{*}{ Monitoramento e Rastreabilidade } & Entre Grupos & 19,591 & 2 & 9,796 & 61,523 &, 000 \\
\hline & Nos grupos & 15,285 & 96 & 0,159 & & \\
\hline & Total & 34,876 & 98 & & & \\
\hline \multirow[t]{3}{*}{ Previsibiliade } & Entre Grupos & 15,141 & 2 & 7,570 & 59,732 &, 000 \\
\hline & Nos grupos & 12,167 & 96 & 0,127 & & \\
\hline & Total & 27,308 & 98 & & & \\
\hline
\end{tabular}

Fonte: Dados da pesquisa.

os indicadores Alfândega $(0,366)$ e Infraestrutura $(0,365)$ são os que têm o melhor poder de discriminação entre os grupos.

Devido os indicadores de desempenho logístico terem sido retirados de um único banco de dados (índice de desempenho logístico - LPI), os mesmos se apresentaram correlacionados e identificou-se o problema de multicolinearidade, como era de se esperar. Desta forma, todos eles contribuem para a formação da função discriminante, porem existe uma explicação repetida entre eles devido esse fato.

Pode-se considerar a retirada de uma ou mais variáveis, conforme orientam Corrar, Paulo e Dias Filho (2017), mas foram feitos testes e isso iria produzir uma função com poder de explicação menor que a atual e deixar de fora variáveis que são importantes para o estudo. Diante disso, conforme os autores orientam, a multicolinearidade não é motivo suficiente para a exclusão de variáveis visto que o processo não foi afetado por completo. Gujarati e Porter (2011) ainda ressaltam que a existência de correlações entre as variáveis explicativas não gera necessariamente estimadores ruins ou fracos e a presença de multicolinearidade não significa que o modelo possui problemas.

Tabela 7 Testes de igualdade de médias dos grupos.

\begin{tabular}{l|c|c|c|c|c}
\hline & $\begin{array}{c}\text { Lambda } \\
\text { de Wilks }\end{array}$ & $\mathbf{z}$ & df1 & df2 & Sig. \\
\hline Alfândega & 0,366 & 83,142 & 2 & 96 & 0,000 \\
\hline $\begin{array}{l}\text { Infraestrutura } \\
\text { Qualidade e Com- } \\
\text { petência Logística }\end{array}$ & 0,408 & 83,441 & 2 & 96 & 0,000 \\
\hline $\begin{array}{l}\text { Carregamentos } \\
\text { Internacionais }\end{array}$ & 0,532 & 42,169 & 2 & 96 & 0,000 \\
\hline $\begin{array}{l}\text { Monitoramento e } \\
\text { Rastreabilidade }\end{array}$ & 0,438 & 61,523 & 2 & 96 & 0,000 \\
\hline Previsibiliade & 0,446 & 59,732 & 2 & 96 & 0,000 \\
\hline
\end{tabular}

Fonte: Dados da Pesquisa. 
Tabela 8 Resultados dos autovalores para cada função.

\begin{tabular}{c|c|c|c|c}
\hline Função & Autovalor & $\begin{array}{c}\text { \% de } \\
\text { variância }\end{array}$ & \% cumulativa & Correlação canônica \\
\hline 1 & 2,326 & 97,4 & 97,4 & 0,836 \\
\hline 2 & 0,062 & 2,6 & 100 & 0,242 \\
\hline
\end{tabular}

Fonte: Dados da pesquisa.

A Tabela 8 evidencia o autovalor, que segundo Marôco (2003) é uma medida relativa de quão diferente os grupos são na função discriminante. Neste caso, o resultado apresentou duas funções que correspondem a $100 \%$ da variância explicada em termos de diferenças entre grupos. Esta Tabela também apresenta a correlação canônica, que demonstra o nível de associação entre os scores discriminantes e os grupos.

A análise dos coeficientes da função de classificação permite conhecer um pouco mais sobre qual a importância de cada indicador dentro da função discriminante (CORRAR; PAULO; DIAS FILHO, 2017). Desta forma, com base nos coeficientes canônicos dispostos na Tabela 8 e considerando que a Função 1 possui maior variância explicada em termos de diferença entre grupos, 97,4\%, os coeficientes de função discriminante canônica se ativeram apenas a essa função, conforme se apresenta na Tabela 9.

A Função $1^{1}$ da Tabela 9 refere-se aos coeficientes não padronizados que apresentam os coeficientes das funções de classificação e servem apenas para classificar as observações entre os grupos e não têm qualquer interpretação discriminante. Já a Função $1^{2}$ representa os coeficientes padronizados da função discriminante, que são obtidos pela multiplicação dos coeficientes não padronizados pelas respectivas raízes de covariâncias para cada variável.

Segundo Marôco (2003), esses coeficientes padronizados, que também são chamados de pesos discriminantes (desconsidera-se o sinal da variável), podem ser utilizados para avaliar a importância relativa de cada variável explicativa para a função discriminante. Assim, variáveis explicativas com grande poder discriminante geralmente apresentam grandes pesos.

De posse dos coeficientes da função discriminante canônica não padronizado (Função $1^{1}$ ), pode-se elaborar a função para a análise discriminante, ou
Tabela 9 Coeficientes de função discriminante canônica.

\begin{tabular}{l|c|c}
\multicolumn{1}{c|}{ Variáveis } & Função 1 & Função $\mathbf{1}^{\mathbf{2}}$ \\
\hline Alfândega & $\mathbf{2 , 3 5 8}$ & $\mathbf{0 , 8 4 7}$ \\
\hline Infraestrutura & $\mathbf{2 , 5 3 3}$ & $\mathbf{1 , 0 3 6}$ \\
\hline Qualidade e Competência Logística & 0,902 & $\mathbf{0 , 3 4 7}$ \\
\hline Carregamentos Internacionais & $\mathbf{- 3 , 4 2 2}$ & $\mathbf{- 1 , 1 7 3}$ \\
\hline Monitoramento e Rastreabilidade & $-1,143$ & $-0,456$ \\
\hline Previsibiliade & 0,598 & 0,213 \\
\hline (Constante) & $-5,371$ & - \\
\hline
\end{tabular}

1 Coeficientes não padronizados

${ }^{2}$ Coeficientes padronizados

Fonte: Dados da Pesquisa.

seja, a equação do modelo de análise para eficiência média. A Equação 2 representa essa função.

$$
\begin{aligned}
\mathrm{Z}= & -5,371+2,358 \text { (Alfândega) } \\
& +2,533 \text { (Infraestrutura) } \\
& +0,902 \text { (Qualidade e Comp.Logística) } \\
& -3,422 \text { (Carregamentos Inter.) } \\
& -1,143 \text { (Monitoramento e Rastreab.) } \\
& +0,598 \text { (Previsibilidade) }
\end{aligned}
$$

As variáveis Carregamentos Internacionais $(-1,173)$, Infraestrutura $(1,036)$ e Alfândega $(0,847)$, nessa ordem de importância obtiveram os maiores coeficientes canônicos padronizados, em módulo, e consequentemente são as variáveis com maior grau de discriminação entre os grupos. Pode-se afirmar que essas variáveis são as mais significativas para os países alcançarem altos níveis de eficiência logística, pode sinalizar aos gestores públicos as prioridades de atenção e investimento entre os indicadores, além de mostrar para os empresários que atuam no comércio 
internacional onde estão os gaps no sistema logístico dos países.

Esses resultados são opostos aos encontrados por Gessner, Rodriguez e Lezana (2018), que embora analisaram apenas o contexto brasileiro, concluíram que o indicador de Previsibilidade apresentou o melhor resultado sendo o mais relevante em termos de competitividade internacional. Já o trabalho de Rezaei, Van Roekel e Tavasszy (2018) apresenta um resultado similar. Esses autores assumem que a Infraestrutura tem maior peso entre os indicadores, porém assume que a Qualidade e Competência Logística está em segundo lugar, fato esse que distingue da presente pesquisa uma vez que esse indicador foi pouco representativo na frente apenas da Previsibilidade.

Por fim, os resultados encontrados pela classificação para a análise discriminante podem ser vistos na Tabela 10. Os casos originais agrupados corretamente representam um percentual de acerto igual a $78,8 \%$, enquanto os casos classificados incorretamente giram em torno de $21,2 \%$.

O nível de precisão global do modelo (78,8\%) classificou corretamente 78 dos 99 países. Dos 45 países tidos com eficiência inferior, $88,9 \%$ foram classificados corretamente e $11,1 \%$ foram classificados incorretamente no grupo de eficiência mediana. Do grupo de 26 países com eficiência mediana, apenas $53,8 \%$ (14 países) foram classificados corretamente, constatando mais uma vez a maior dispersão desses dados conforme visto na Tabela 4. E por último o grupo dos países mais eficientes, 85,7\% (24 países dos 28 do grupo) foram classificados corretamente, sendo apenas 1 classificado incorretamente como de eficiência inferior e 3 classificados incorretamente como de eficiência mediana.

\section{CONCLUSÃO}

O estudo baseou-se na análise da eficiência logística dos países e sua relação com os indicadores de desempenho logístico - LPI. O objetivo foi avaliar a eficiência logística dos países considerando os aspetos institucionais e estruturais, bem como criar scores que represente o peso de cada indicador LPI nessa eficiência.

A análise dos dados permitiu constatar o nível de eficiência logística dos 99 países com maiores PIBs per capta que constavam na pesquisa LPI dos anos de 2014, 2016 e 2018. Os países mais eficientes foram Luxemburgo e Noruega, enquanto os piores colocados no ranking foram a Papua Nova Guiné e o Egito. O Brasil estava na $48^{\text {a }}$ posição no ano de 2014 e caiu para a $52^{\mathrm{a}}$ em 2018, perdendo assim $17,43 \%$ de sua eficiência logística no período em questão.

Foram criados níveis de eficiência no intuito de agrupar os países em faixas inferior, mediana e superior de eficiência, onde 28 foram classificados como tendo alta eficiência, 26 países com eficiência mediana e a maioria deles, 45 países, classificados com eficiência inferior e que demandam maior atenção institucional e estrutural no setor logístico.

Para verificar se os indicadores apresentavam diferenças estatísticas significativas para discriminar

Tabela 10 Resultados da classificaçãoa.

\begin{tabular}{|c|c|c|c|c|c|c|}
\hline & & \multirow{2}{*}{$\begin{array}{l}\text { Eficiência } \\
\text { Média }\end{array}$} & \multicolumn{3}{|c|}{ Associação ao grupo prevista } & \multirow{2}{*}{ Total } \\
\hline & & & Inferior & Mediana & Superior & \\
\hline \multirow[t]{6}{*}{ Original } & \multirow[t]{3}{*}{ Contagem } & Inferior & 40 & 5 & 0 & 45 \\
\hline & & Mediana & 9 & 14 & 3 & 26 \\
\hline & & Superior & 1 & 3 & 24 & 28 \\
\hline & \multirow[t]{3}{*}{$\%$} & Inferior & $88,90 \%$ & $11,10 \%$ & $0 \%$ & $100 \%$ \\
\hline & & Mediana & $34,60 \%$ & $53,80 \%$ & $11,50 \%$ & $100 \%$ \\
\hline & & Superior & $3,60 \%$ & $10,70 \%$ & $85,70 \%$ & $100 \%$ \\
\hline
\end{tabular}

a $78,8 \%$ de casos agrupados originais classificados corretamente.

Fonte: Dados da pesquisa. 
os três grupos de eficiência logística, foi realizado o teste ANOVA de um fator que constatou a existência da diferença entre os grupos e que os indicadores possuem médias diferentes entre os grupos. A partir dessa evidência pode-se criar regras para identificar os países com eficiência média inferior, mediana e superior.

Por fim, a análise discriminante criou scores para destacar os indicadores LPI que mais impactam no desempenho logístico, sendo a Alfândega e a Infraestrutura, relacionados com as regulações políticas, e os Carregamentos Internacionais ligados ao desempenho das prestadoras de serviço, os indicadores mais significativos na busca pela eficiência logística máxima dos países. Isto comprova a importância e a ligação dos fatores institucionais com a logística dos países, apresentando uma contribuição de grande relevância para a área em estudo.

Os resultados encontrados nessa pesquisa trazem algumas implicações que merecem destaque. Do ponto de vista econômico e social, a eficiência logística não afeta apenas a produtividade dos países, mas pode impactar o desenvolvimento econômico como um todo, dificultando as importações e exportações, o escoamento dos produtos para as diversas regiões, sendo um empecilho para os investidores aplicarem no país e inibir a geração de renda nas cidades de difícil acesso e menos desenvolvidas.

Os resultados mostram os indicadores logístico que mais impactam na distinção entre países menos eficientes e mais eficientes. Esse indicativo é um interessante resultado que mostra os pontos centrais que merecem mais atenção por parte dos empresários e representantes políticos na busca da máxima eficiência logística, além de ranquear os países quanto a eficiência e permitindo fazer benchmarking com os mais eficientes.

No que tange o aspecto acadêmico, este trabalho contribui em apresentar uma relação metodológica entre a DEA e a análise discriminante para compreender a eficiência logística dos países. Esse pode ser o ponto de partida para uma análise mais detalhada da importância dos indicadores logístico segundo a particularidade de cada nação. Estudar os aspectos referentes à eficiência logística assume crescente relevância no atual cenário econômico de instabilidade e de um mercado internacional cada vez mais abrangente.

Vale ressaltar também que as evidências encontradas e discutidas nesta pesquisa devem ser consideradas levando em conta os critérios de seleção da amostra (99 países analisados no período de 2014 a 2018) e as limitações da metodologia adotada. Há limitações nos indicadores de input e output utilizados para mensurar a eficiência, uma vez que estes capturam apenas os aspectos que estão relacionados aos indicadores logísticos que foram utilizados. Além disso, o método DEA apresenta objetivos e critérios específicos para estimar a eficiência e podem não capturar todos os aspectos envolvidos por esse conceito.

Como sugestão para trabalhos futuros na área, recomenda-se investigar quais as variáveis que são determinantes na eficiência logística dos países utilizando os scores dessa pesquisa como variáveis dependentes em modelos econométricos, de forma a identificar as variáveis de investigação que se relacionam diretamente com essa eficiência. Recomenda-se também uma análise no mercado brasileiro a fim de identificar o setor industrial que é mais impactado pela estrutura logística do país.

\section{REFERÊNCIAS}

\section{BALLOU, R. H. Gerenciamento da cadeia de supri- mentos: Logística Empresarial. 5. ed. Porto Alegre: Bookman, 2006.}

BANCO MUNDIAL. 2020. Disponível em: <https://www.bancomundial.org/es/country/panama>. Acesso em: 03 mar. 2020.

BANCO MUNDIAL. Connecting to compete 2016: trade logistics in the global economy. Disponível em: $<$ https://lpi.worldbank.org/>. Acesso em: 21 jan. 2019.

BANCO MUNDIAL. Connecting to compete 2018: trade logistics in the global economy. Disponível em: < https://lpi.worldbank.org/>. Acesso em: 21 jan. 2019. 
BAZANI, C. L. Desempenho logístico do Brasil no mercado internacional: análise do índice LPI. 2017. 116 p. Dissertação (Mestrado em Ciências Contábeis) - Universidade Federal de Uberlândia, Uberlândia. 2017.

BIZOTTO, B. L. S.; COSTA, C. A.; RUI, C.; LAZZAROTTO, E.; RECHE, R. A.; CAMARGO, M. E. Estudo de Caso dos Impactos da Crise Global nos Critérios Competitivos Estratégicos de Empresas. Revista Gestão Industrial. v. 07, n. 1, p. 23-42, 2011.

CIA.GOV. 2020. Disponível em: <https://www.cia. gov/library/publications/the-world-factbook/geos/ lu.html >. Acesso em: 02 abr. 2020

CABRAL, S.; SILVA JÚNIOR, A. F. Escolhas estratégicas para expansão de uma malha ferroviária: uma análise baseada em opções reais. Revista Base (Administração e Contabilidade) da UNISINOS, [S.1.], v. 8, n. 1, p. 78-90, 2011.

CARLSSON, R.; OTTO, A.; HALL, J. W. The role of infrastructure in macroeconomic growth theories. Civil Engineering and Environmental Systems. v. 30, n. 3-4, p. 263-273, 2013.

CAVANHA FILHO, A. O. Userchain: end user logistics. 2. ed. Houston: Petrobras, 2008.

CHARNES, A.; COOPER, W. W.; RHODES, E. Measuring the efficiency of decision making units. European Journal of Operational Research, v.2, n. 6, p.429-444, 1978.

CORRAR, L. J.; PAULO, E.; DIAS FILHO, J. M. (Coord). Análise multivariada: para os cursos de administração, ciências contábeis e economia. São Paulo: Atlas, 2017.

CSCMP - COUNCIL OF SUPPLY CHAIN MANAGEMENT PROFESSIONALS. Supply chain and logistics terms and glossary. 2009. Disponível em: <https://cscmp.org/supply-chain-management-definitions> Acesso em: 08 dez. 2018.
DYSON, R. G.; ALLEN, R.; CAMANHO, A. S.; PODINOVSKI, V. V.; SARRICO, C. S.; SHALE, E. A. Pitfalls and protocols in DEA. European Journal of Operational Research, v. 132, n. 2, p. 245-259, 2001.

ENG-LARSSON, F.; LUNDQUIST, K. J.; OLANDA, L. O., WANDEL, S. Explaining the cyclic behavior of freight transport $\mathrm{CO} 2$ emissions in Sweden over time. Transport Policy, The Hague, v. 23, p. 79-87, 2012.

FARRELL, M. J. The measurement of productive efficiency. Journal of the Royal Statistical Society: Series A (General), v. 120, n. 3, p. 253-281, 1957.

FÁVERO, L. P.; BELFIORE, P. Manual de análise de dados. 1. ed. Rio de Janeiro: Elsevier, 2017.

FIELD, A. Descobrindo a estatística usando o SPSS. Porto Alegre: Artmed, 2013.

GESSNER, E.; RODRIGUEZ, C. M. T.; LEZANA, Á. G. R. Desempenho Logístico do Brasil entre $2007 \mathrm{E}$ 2018: Análise com base no Índice de Desempenho Logístico do Banco Mundial. Brazilian Journal of Production Engineering-BJPE, v. 4, n. 3, p. 150168, 2018.

GOMES, C. F. S.; RIBEIRO, P. C. C. Gestão da cadeia de suprimentos integrada à tecnologia da informação. São Paulo: Pioneira Thomson Learning, 2004.

GUJARATI, D. N.; PORTER, D. C. Econometria Básica. 5. ed. McGraw Hill Brasil, 2011.

HAIR, J. F.; BLACK, W. C.; BABIN, B. J.; ANDERSON, R. E.; TATHAM, R. L. Análise multivariada de dados. 6. ed. Porto Alegre: Bookman, 2009.

KABAK, Ö.; ÜLENGIN, F.; EKICI, Ş. Ö. Connecting logistics performance to export: A scenario-based approach. Research in Transportation Economics, v. 70, p. 69-82, 2018.

LAU, K. H. Benchmarking green logistics performance with a composite index. Benchmarking: An International Journal, v. 18, n. 6, p. 873-896, 2011. 
MARIANO, E. B.; GOBBO JR, J. A.; DE CASTRO CAMIOTO, F.; DO NASCIMENTO REBELATTO, D. A. $\mathrm{CO} 2$ emissions and logistics performance: a composite index proposal. Journal of Cleaner Production, v. 163, p. 166-178, 2017.

MARIN, T.; VIEIRA, G. B. B.; VERRUCK, F.; DA SILVA, R. M. A Relação entre a Implementação do Programa Operador Econômico Autorizado e o Índice de Performance Logística dos Países. Gestão \& Regionalidade, v. 35, n. 104, 2019.

MARKOVITS-SOMOGYI, R.; BOKOR, Z. Assessing the logistics efficiency of European countries by using the DEA-PC methodology. Transport, v. 29, n. 2, p. 137-145, 2014.

MARÔCO, J. Análise Estatística: com utilização do SPSS. 2. ed. Lisboa: Edições Sílabo, 2003.

MARÔCO, J. Análise de equações estruturais: Fundamentos teóricos, software \& aplicações. 2. ed. Pêro Pinheiro: Report Number, 2014.

MARTÍ, L.; MARTÍN, J. C.; PUERTAS, R. A DEAlogistics performance index. Journal of Applied Economics, v. 20, n. 1, p. 169-192, 2017.

MARTÍ, L.; PUERTAS, R.; GARCÍA, L. The importance of the Logistics Performance Index in international trade. Applied Economics, v. 46, n. 24, p. 2982-2992, 2014.

MATEUS, R. S. Análise de insolvência empresarial: uma abordagem financeira fundamentalista com aplicação do método estatístico multivariado e da técnica discriminante. 2010. 79 p. Dissertação (Mestrado Profissional em Desenvolvimento Regional e Gestão de Empreendimentos Locais) - Universidade Federal de Sergipe, São Cristóvão, 2010.

OCDE - Organização para a Cooperação e Desenvolvimento Econômico. 2020. Disponível em: <http://www.oecd.org/>. Acesso em: 03 mar. 2020.
OLIVEIRA, J. de S. A relação entre inovação e produtividade nas empresas hoteleiras-uma perspectiva de análise utilizando a análise envoltória de dados (DEA) e a modelagem de equações estruturais (SEM). 2018. 352 p. Tese (Doutorado em Administração) Escola de Administração de Empresas de São Paulo, São Paulo, 2018.

REY, M. F. Indicadores de desempenho logístico. Revista Logmam, v. 30, n. 10, p. 18-23. 1999.

REZAEI, J.; VAN ROEKEL, W. S.; TAVASSZY, L. Measuring the relative importance of the logistics performance index indicators using Best Worst Method. Transport Policy, v. 68, p. 158-169, 2018.

SARKIS, J. Preparing Your Data for DEA: Modeling Data Irregularities and Structural Complexities in Data Envelopment Analysis. Nova York: Springer, 2007.

SOLIANI, R. D. Evaluation of the Brazilian Logistic Performance in the LPI Index. European International Journal of Science and Technology, v.7, n. 8, p. 35-48, 2018.

WACZIARG, R.; WELCH, K. H. Trade liberalization and growth: new evidence. World Bank Economic Review, v. 22, n. 2, p. 187-231, 2008. 